\title{
Sex differences in response to dietary carbohydrates
}

\section{By I. Macdonald, Department of Physiology, Guy's Hospital Medical School, London $S E_{1} g R T$}

Until recent times it was considered that the type of carbohydrate consumed did not influence the metabolism, as all carbohydrates were converted to glucose. This idea has now been dismissed and the question has arisen as to whether the metabolic response to a particular carbohydrate in the diet can be modified in any way by variables such as the sex of the consumer.

Interest in the metabolic role of the dietary carbohydrates has sharpened since the observation that an increase in the intake of carbohydrate may lead to an increase in the serum concentration of triglyceride in fasting subjects (Ahrens, Hirsch, Oettle, Farquhar \& Stein, 196r). That there is a difference between men and women in their response to carbohydrate would be consistent with the observation that the mean level of fasting serum triglyceride is not similar in men and women. Epidemiological studies have shown that there is a higher proportion of raised levels of fasting triglyceride in men than in women, until after the age of 60 years, when the difference in incidence becomes less apparent (Wood, Stern, Silvers, Reaven \& von der Groeben, 1972; Lewis, Chait, Wootton, Oakley, Krikler, Sigurdsson, February, Maurer \& Birkhead, 1974). These findings would be compatible with a difference in the metabolism of the carbohydrate between men and premenopausal women.

\section{Differences following acute administration of carbohydrates}

More direct evidence that a sex difference exists in the response to dietary carbohydrates is seen in the variations found in the glucose-tolerance test during the menstrual cycle (Macdonald \& Crossley, 1970). The glucose level is significantly greater at days $13-18$ of the cycle than at days $7-12$, suggesting that hormonal fluctuations are in some way associated with this variation. This change in the blood glucose response may not, however, reflect any alterations in the metabolism of glucose and may be due to altered gastrointestinal activity known to occur under the influence of female sex hormones (Macdonald, 1956).

In order to decide whether the differences were due to gastrointestinal or metabolic factors, glucose and fructose were given intravenously to male and female baboons and the subsequent levels of the sugars and of triglyceride in the serum measured. It was found that in mature male baboons the fructose in the serum disappeared at a faster rate than in the mature female animals, whereas in immature females the rate of disappearance was similar to that in the males 
(Jourdan, 1969a). No such difference was found between the sexes after the infusion of glucose. After giving radioactive fructose to these animals it was found that the specific activity of the serum triglyceride fraction was greater in the male than in the female baboons. After $\left[{ }^{14} \mathrm{C}\right]$ glucose injection not only was the specific activity in the triglycerides significantly less than that found after $\left[{ }^{14} \mathrm{C}\right]$ fructose injection, but no difference between the sexes was detected (Jourdan, 1969b).

To lend support to the view that this difference in response to fructose was of metabolic rather than digestive origin a large single dose of sucrose was given, by mouth, to young men and women, and it was found that those men who had high fasting serum triglyceride concentrations prior to sucrose ingestion developed high levels of serum glucose and fructose after the sucrose meals. No such correlation was found in the young women, thus suggesting further that the difference in response to carbohydrate between men and women is metabolic in origin (Crossley, 1967).

\section{Differences following chronic ingestion}

In 1964 it was first reported that the dietary carbohydrate-lipid interrelationship was influenced by the sex of the consumer (Beveridge, Jagannathan \& Connell, 1964). In these experiments male students showed a significant rise in serum triglycerides in the fasting state while on a highcarbohydrate diet, whereas the female students showed no such change. This difference in the response in the serum concentration of endogenous triglyceride was confirmed and shown to apply mainly to the fructose component of the dietary carbohydrate (Macdonald, r 966). As might be expected, the difference in the triglyceride response between men and women was not present when the women were postmenopausal.

It is known that oestrogen administration is associated with an increase in the concentration of triglyceride in the fasting serum, possibly due to an increased production rate (Glueck, Fallat \& Scheel, 1975). This would appear to be contrary to the fact that lower levels of endogenous triglyceride are found in young women compared with men of the same age (see above) but compatible with the increase in fasting serum triglyceride concentration in pregnancy. The roles of progestogen and chorionic gonadotropin are unclear, though it is suggested that progesterone increases triglyceride clearance (Kissebah, Harrigan \& Wynn, 1973). The advent of the oral contraceptive containing oestrogen (synthetic) and progestogen, and the fact that women using the 'pill' have raised fasting serum triglyceride levels and an impaired glucose tolerance (Wynn \& Doar, 1969) would suggest that the usual response of young women to dietary carbohydrate might be altered. Following the ingestion of fructose both the serum triglyceride and serum glucose levels are increased to a greater extent in women using a combined oral contraceptive than in controls (MacRae, 1974).

In monkeys of both sexes which were given diets high in carbohydrates while receiving an oral contraceptive it was found that the level of serum triglyceride was significantly higher than when the oral contraceptive accompanied a stock diet. 
Also the fall in serum cholesterol seen with a high-glucose diet did not occur when the diet was accompanied by an oral contraceptive (Stovin \& Macdonald, 1975).

In an attempt to learn the role of oestrogen and of progestogen either alone or together, rats were given high-sucrose diets and received injections of either oestrodiol, progesterone, or both together, and from the results it appeared that a synergism exists between the two hormones used (Jeffreys \& White, 1973). Oestradiol alone increase the incorporation of sucrose into adipose tissue and progesterone did not seem to have any definite actions when given alone. However, oestradiol and progesterone given together to these animals on a highsucrose diet raised the liver and serum concentrations of triglyceride, whereas either hormone given separately had little effect on these measurements.

Though the evidence at the moment is scanty, such that there is suggests that the interrelationship between dietary carbohydrates (especially fructose) and lipid metabolism is influenced by the sex of the consumer and by the therapeutic use of sex hormones. No clinical consequences of this sexually modified metabolic response have yet been shown.

\section{REFERENCES}

Ahrens, E. H., Hirsch, S., Oettle, K., Farquhar, J. W. \& Stein, Y. (1961). Trans. Ass. Am. Physns 74, 134 .

Beveridge, J. M. R., Jagannathan, S. N. \& Connell, W. F. (1964). Can. F. Biochem. 42, 999. Crossley, J. N. (1967). Proc. Nutr. Soc. 26, iii.

Glueck, C. J., Fallat, R. W. \& Scheel, D. (1975). Metabolism 24, 537.

Jeffrys, D. B. \& White, I. R. (1973). Proc. Nutr. Soc. 32, 60A.

Jourdan, M. H. (1969a). Proc. Nutr. Soc. 28, IoA.

Jourdan, M. H. (1969b). Proc. Nutr. Soc. 28, 63A.

Kissebah, A. H., Harrigan, P. \& Wynn, V. (1973). Horm. metab. Res. 5, 184.

Lewis, B., Chait, A., Wootton, I. D. P., Oakley, C. M., Krikler, D. M., Sigurdsson, G., February, A., Maurer, B. \& Birkhead, J. (1974). Lancet i, 141.

Macdonald, I. (1956). Gastroentrology 30, 602.

Macdonald, I. (1966). Am. F. clin. Nutr. 18, 369 .

Macdonald, I. \& Crossley, J. N. (1970). Diabetes 19, 410.

MacRae, A. R. (1974). Studies of metabolism consequent upon the acute ingestion of carbohydrates in primates. PhD Thesis, University of London.

Stovin, V. \& Macdonald, I. (1975). Proc. Nutr. Soc. 34, 55A.

Wood, P. D. S., Stern, M. P., Silvers, A., Reaven, G. M. \& von der Groeben, J. (1972). Circulation 45, II 4 .

Wynn, V. \& Doar, J. W. H. (1969). Lancet ii, 761. 